\title{
LA PREDECIBILIDAD DE LAS DECISIONES JUDICIALES*
}

\author{
María Isabel Garrido Gómez**
}

\begin{abstract}
RESUMEN
El tema que estudio es la predecibilidad de las decisiones judiciales, ligada a los valores de la libertad, la seguridad y la igualdad. El punto de partida es el de que el principio jurisdiccional que guía la actividad de los jueces es ejercer la garantía de cierre del sistema mediante la corrección de los márgenes de desviación e ilegitimidad jurídicas en las que se hubiera podido incurrir. Desde esta perspectiva, me ocupo del marco en el que se ha de construir la teoría y la práctica de la predecibilidad de tales decisiones dentro de un Estado de Derecho, y del juego concatenado de los valores indicados. Para analizar el juego, me adentro en la cuestión de la motivación de las sentencias, la discrecionalidad judicial, los elementos y significados de la seguridad jurídica y los precedentes; profundizando en el tratamiento dado a la predecibilidad del Derecho por el realismo jurídico norteamericano, especialmente por Frank y Llewellyn.
\end{abstract}

En general, se advierte que los cambios que sufre el modelo aplicativo del Derecho rompen con la concepción del estricto formalismo, creándose espacios relacionados con fines y estrategias no jurídicas. Por consiguiente, se comprende que tenía razón el realismo jurídico norteamericano a la hora de conceptuar el Derecho como realidad que sufre un cambio incesante, apoyado en la actividad judicial creativa. En este sentido, queda patente que no se produce sólo por el legislador, sino que también toma parte el juez. Su creación se reenvía a la

Este trabajo ha sido realizado en el marco del Programa Consolider-Ingenio 2010 "El tiempo de los derechos" del Ministerio de Ciencia e Innovación de España. CSD2008-00007, y del Proyecto sobre "Historia de los derechos fundamentales. Siglo XX" (DER-2008-03941/JURI), del Plan Nacional de Investigación científica, Desarrollo e Innovación tecnológica (2008-2010). Trabajo recibido con fecha 29 de enero de 2009, y aprobado el 7 de abril del mismo año.

** Doctora en Derecho. Profesora Titular de Filosofía del Derecho, Universidad de Alcalá (España). Directora de la Cátedra de Democracia y Derechos Humanos de la citada Universidad y el Defensor del Pueblo de España. Correo electrónico: misabel.garrido@uah.es 
interpretación de la norma aplicable y a que la norma particular en la que deriva la decisión no es efecto de la lógica.

\begin{abstract}
The issue addressed in this study is the predictability of judicial decisions, linked to the values of liberty, the feeling of security it affords people, and equality. The jurisdictional principal guiding judges is to exercise the guarantee of closure of the system by correcting the margins of legal deviation and illegitimacy that might have occurred. From this perspective, I am addressing the framework in which the theory and practice of the predictability of said decisions within a democratic State must be built, and of the concatenate play of the values outlined. In order to analyse the play, I examine the issue of the reasoning informing rulings, legal discretionality, the meanings and elements of legal security and precedents. The treatment given to the predictability of the Law by American Legal Realism, especially by Frank and Llewellyn, is gone into in greater depth.

Lastly, I must point out that the changes undergone by the applicative Law model break with the concept of strict formalism, and spaces related to non-legal purposes and strategies are created. Consequently, it may be understood that American Legal Realism was right in regarding the Law as a reality that undergoes unceasing changes, owing to creative legal activity. In this regard, it is made clear that legislators and judges alike play a part in this process. Its creation goes back to the interpretation of the regulation in force and to the fact that the specific regulation on the basis of which the decision is made is not a consequence of logic.
\end{abstract}

PALABRAS CLAVES

Predecibilidad, discrecionalidad judicial, seguridad jurídica

KEYWORDS

Predictability, judicial discretionality, legal security

\title{
1. Introducción
}

Dentro de los estudios actuales de Teoría del Derecho, se aprecia que la investigación de todo lo que se refiere a las decisiones judiciales, ya sea en relación a su concepto, a su naturaleza, a la forma de practicarse, etc., despierta un gran interés en los planos teórico y práctico. Por tanto, abordaré una de estas vertientes, en concreto, el tema del que me ocuparé será el de la predecibilidad de las decisiones de los jueces. Dicha predecibilidad plantea grandes problemas e incógnitas que permanecen aún sin resolver y que tienen sus raíces en razones dispares, tales como la diferencia entre los resultados a los que llegamos según partamos de una teoría escéptica o no escéptica, la posición que se defienda en lo relativo al poder creador del Derecho por 
parte del juez, cuáles son los límites de la discrecionalidad judicial, el tipo de juez que resuelva un caso o, muy particularmente, la operatividad de los precedentes judiciales.

A lo largo de la investigación, surgen los siguientes interrogantes: ¿cómo controlar la regularidad y la objetividad de las consideraciones realizadas?, y ¿cómo impedir que la libertad estimativa no desemboque en arbitrariedad? En conexión con estos postulados, el valor que posee la predecibilidad de las decisiones judiciales se liga a la seguridad que produce en sus destinatarios, añadiéndose a los anteriores interrogantes los siguientes: ¿son predecibles tales decisiones?, ¿de qué tipo de predecibilidad hablamos?, ¿es posible lograr que lo sean?, o ¿es predicable la seguridad del Derecho judicial?

Como punto de arranque, se podría decir que el principio jurisdiccional que guía la actividad de los órganos que estudiamos es el ejercer la garantía de cierre del sistema mediante la corrección de los márgenes de desviación e ilegitimidad jurídicas en que otros poderes o los otros individuos hubieran podido incurrir. En definitiva, las garantías jurisdiccionales se desdoblan en dos dimensiones, en la medida en que suponen una corrección jurídica y aportan una solución a los conflictos de derechos e intereses ${ }^{1}$, siendo el problema de fondo si los jueces están legitimados para producir Derecho.

\section{Las decisiones judiciales dentro de un Estado de Derecho}

Las soluciones judiciales en el seno de un Estado de Derecho deben tener en cuenta los valores e intereses en pugna, calificados por el legislador previamente con carácter general y abstracto. Desde esta perspectiva, el Derecho positivo tiene que responder a una sistematicidad constructiva de un mecanismo de seguridad que remita a valores, como la libertad, la seguridad y la igualdad ${ }^{2}$. En este sentido, por medio de la motivación de las sentencias, se pretende que el juzgador manifieste las razones de su decisión apoyándose en el derecho del justiciable y del interés legítimo de la comunidad en conocerlas; que se compruebe que la decisión judicial que se adopta es consecuencia de una exégesis racional del Ordenamiento; que las partes o la comunidad tengan la información necesaria para recurrir, si procede, la decisión; y que los tribunales competentes posean la información que se precisa para vigilar la correcta interpretación y aplicación del Derecho ${ }^{3}$.

Efectivamente, en los Estados de Derecho contemporáneos, la motivación de las sentencias es una exigencia de los derechos fundamentales para que no se produzca la arbitrariedad del

Peña Freire, Antonio María, La garantía en el Estado constitucional. Ed. Trotta, Madrid, 1997, pp. 228 y ss. Atienza, Manuel, Contribución a una teoría de la legislación. Ed. Civitas, Madrid, 1997, p. 32.

Asís Roig, Rafael de, Jueces y normas. La decisión judicial desde el Ordenamiento. Ed. Marcial Pons, Madrid, 1995, p. 111. 
Poder, para controlarlo y para garantizar jurídicamente los derechos y libertades de los ciudadanos. La justificación judicial en el plano interno consiste en que la resolución del juez se infiera de sus premisas conforme a las líneas de inferencia que han sido aceptadas, dándose un razonamiento lógico que dirige la conclusión prevista en el fallo. Sin embargo, se requiere una justificación externa cuando las premisas de hecho y normativas, o ambas de forma simultánea, precisan de argumentaciones nuevas, siendo completa la motivación cuando contiene los dos planos ${ }^{4}$. En esta línea, dice Gascón Abellán que "motivar exige aportar razones lo bastante sólidas para descartar la arbitrariedad y, por consiguiente, también (o sobre todo) las que no avalan la reconstrucción de los hechos que se justifican: la justificación no será completa si no se justifica también por qué no se han atendido estas pruebas" ${ }^{5}$.

Pero, yendo más allá, las razones se deben a la necesidad de garantizar los derechos de quien es parte en un proceso. Un primer grupo de razones se explica porque es una garantía del justiciable mediante la cual, sin perjuicio de la libertad del juez en la interpretación de las normas, se puede comprobar que la solución dada al caso es derivación de una exégesis racional del Ordenamiento y no el fruto de la arbitrariedad. Con respecto a una segunda clase de razones, tendríamos que suscribir que un Estado de Derecho implica que los poderes públicos queden sometidos al Derecho y que los órganos jurisdiccionales ejerzan su control, control que sólo se legitima en la aplicación del Derecho y de ahí la necesidad de que hayan de motivar sus resoluciones. Desde la visión del Estado democrático, lo que se pretende es el convencimiento de las partes y de la opinión pública, por lo que si el Poder judicial emana del pueblo, entonces éste debe conocer la forma en la que se ejerce para controlar a sus titulares ${ }^{6}$.

Así, la racionalidad se pormenoriza en función de la consideración de las normas y de los hechos. Los jueces deben razonar discurriendo razones comunicadas argumentativamente y el respeto a la ley no garantiza la racionalidad decisional. La norma puede ser irracional en su contenido, fuera de que en el proceso aplicativo influyan elementos externos, y de que, a menudo, se funde en los criterios de oportunidad y de utilidad ante un conflicto de derechos con la satisfacción del mayor número posible de personas ${ }^{7}$.

4 Gascón Abellán, Marina, Los hechos en el Derecho. Bases argumentativas de la Prueba. Ed. Marcial Pons, Madrid, 2004, pp. 193 y 194.

Gascón, Los hechos, cit., nota n. 4, pp. 227 y 228.

Gómez Montoro, Ángel José, "El derecho a una resolución motivada y congruente en la jurisprudencia del Tribunal Constitucional”, en Aragón Reyes, Manuel y Martínez-Simancas, Julián (dirs.), La Constitución y la práctica del Derecho, t. 1, Ed. Aranzadi-BCH, Pamplona, 1998, pp. 492 y ss.

Atienza, Manuel, Tras la justicia. Una introducción al Derecho y al razonamiento jurídico. Ed. Ariel, Barcelona, 1997, pp. 242 y 243; Ezquiaga Ganuzas, Francisco Javier, “Iura novit curia” y aplicación judicial del Derecho. Ed. Lex Nova, Valladolid, 2000, pp. 216 y ss.; Segura Ortega, Manuel, La racionalidad jurídica. Ed. Tecnos, Madrid, 1998, pp. 118-120. 
Especificando más, estas ideas no se pueden hacer inteligibles de modo integral si no las enmarcamos en el terreno de la discreción judicial, cuyo elemento principal es la elección entre diversas posibilidades reales mutuamente excluyentes, de manera que, en un sentido fuerte, tener discreción significaría que no hay una respuesta correcta. La vinculación recae en la presencia o ausencia de ciertos hechos relacionados con los comportamientos lingüísticos en una comunidad o los actos normativos de una autoridad ${ }^{8}$, y las decisiones judiciales terminan con un fallo que debe justificarse en una norma general. La resolución no puede ser arbitraria, se ha de deducir de las normas previas y de los hechos, aun cuando el juez cree normas generales, decidiendo desde varias de ellas y construyendo un enunciado. Ahora bien, la duda es si son parte del Ordenamiento jurídico. En este nivel de análisis, la respuesta hay que vincularla, entre otros factores, con los distintos sentidos que tiene la actividad interpretativa.

Al hilo de esta afirmación, la Jurisdicción representa una actividad racionalizadora dirigida a los titulares del derecho a la jurisdicción, siendo de especial importancia a quién le corresponde decir la última palabra en materia de Derecho, lo cual se conecta con la soberanía y el origen del Ordenamiento ${ }^{9}$. Se debe tener en cuenta que, a la hora de abordar si las decisiones judiciales son predecibles, la complejidad crece y se produce alguna confusión porque los modelos de conexión son muy diversos, conllevando respuestas igualmente diferentes según sea la relación entre los jueces y la esfera socio-política. Esa tipología se resume en: El juez ejecutor, con "baja creatividad judicial y baja autonomía política", el cual aplica simplemente la voluntad legislativa. Este tipo ha sido sustituido por el modelo "consensual", que defiende la aplicación del Derecho conformada por el punto de vista de la sociedad. El juez guardián, con "baja creatividad jurisprudencial y alta autonomía política", caso en el que la aplicación judicial se apoya en los derechos de las partes. El juez delegado, con "alta creatividad jurisprudencial y baja autonomía política", el cual procede cuando no existe una respuesta clara de las normas jurídicas, sometido a límites mucho mayores y más rígidos que el legislador. Y el juez político, con "alta creatividad jurisprudencial y alta autonomía política", característico del realismo jurídico norteamericano y del movimiento Critical Legal Studies ${ }^{10}$.

De ahí, se advierte que, en cada modelo, la discrecionalidad judicial actúa de forma más o menos intensa. Todo esto plantea problemas en relación con la certeza jurídica y, de forma más amplia, en relación con la seguridad. Realmente, la seguridad ha dejado de ser contemplada, cada vez más, como un valor enemistado con la justicia para pasar a ser observada como un

8 Alchourrón, Carlos E. y Bulygin, Eugenio, Introducción a la metodología de las ciencias jurídicas y sociales. Ed. Astrea, Buenos Aires, 2006, pp. 63-65; Prieto Sanchís, Luis, Ideología e interpretación jurídica. Ed. Tecnos, Madrid, 1993, pp. 90-92.

9 Ciuro Caldani, Miguel Ángel, Filosofía de la jurisdicción: con especial referencia a la posible constitución de un Tribunal judicial del MERCOSUR. Rosario (Argentina), 1998, p. 77.

10 Rodríguez-Toubes Muñiz, Joaquín, Principios, fines y derechos fundamentales. Instituto de Derechos Humanos "Bartolomé de las Casas" de la Universidad Carlos III de Madrid-Ed. Dykinson, Madrid, 2000, pp. 112-114. 
conjunto de dimensiones éticas que vendrían a formar parte de la justicia formal ${ }^{11}$. No hay duda, pues, de que las exigencias de la seguridad del Derecho constituyen un medio idóneo para garantizar el respeto de algunos valores cuya realización se evalúa imprescindible para el logro de un orden social justo. De esta forma, las exigencias de la seguridad del Derecho permiten crear algunos de los presupuestos de la libertad. Un orden jurídico estructurado con arreglo a esos requerimientos introduce en el ambiente de las relaciones públicas y privadas unos parámetros ciertos, fijos y previsibles, que posibilitan un ejercicio confiado de la iniciativa y libertad personales.

Dentro de este marco, Rawls ${ }^{12}$ ha declarado que un orden jurídico que cumpla del modo más perfecto los preceptos del Rule of Law asegura una base más firme para la libertad. Cuanto más públicas, claras, irretroactivas..., sean las leyes, más protegida estará la libertad de los individuos. La razón de esa creencia es que las normas jurídicas constituyen pilares mediante los que las personas confían unas en otras y ejercen sus derechos cuando sus expectativas no se cumplen. Si los cimientos de estas expectativas son inseguros, también lo son los límites de la libertad humana. Sus peligros son menores cuando la ley es administrada imparcial y regularmente y se sabe qué cosas castiga y qué cosas entran o no dentro de su poder de actuación, ya que los ciudadanos pueden entonces proyectar sus planes conjuntamente.

\section{Elementos y significados de la seguridad jurídica que fundamentan la predecibilidad de las decisiones judiciales}

Los elementos centrales de la seguridad jurídica como valor fundante de la predecibilidad de las decisiones judiciales son: la certeza jurídica, la eficacia jurídica y la ausencia de arbitrariedad. Ellos representan los términos más simples del lenguaje de la seguridad, de forma que todos los principios que suelen aparecer vinculados (publicidad, claridad, irretroactividad, etc.) pueden contemplarse como instrumentos de certeza y/o eficacia, y/o interdicción de la arbitrariedad.

Como desarrollo de los elementos precedentes, un primer conjunto de significados de la seguridad del Derecho puede ser englobado bajo el término certeza jurídica. Aunque entre ellos hay una gran proximidad y, fácticamente, se superponen de manera parcial, es conveniente distinguir cuatro manifestaciones: la certeza de orientación, la certeza de existencia, la predecibilidad jurídica y la firmeza del Derecho. En relación a la certeza de orientación y a la certeza de existencia, la seguridad del Derecho es, en primer lugar, certeza o certidumbre

11 Lyons, David, “On formal justice”, en Moral Aspects of Legal Theory. Essays in Law, Justice and Political Responsability, Cambridge University Press, Nueva York, 1993, pp. 13 y ss.

12 Rawls, John, Teoría de la justicia, trad. de M.D. González Soler. Ed. Fondo de Cultura Económica, Madrid, 2002, pp. 222 y ss. 
jurídica. Para Geiger ${ }^{13}$, sería la circunstancia de que se conozca lo que está en el Ordenamiento, el saber acerca de las normas jurídicas o la cognoscibilidad de su contenido libre de dudas, lo cual permite a los ciudadanos conocer lo que está prohibido, impuesto o permitido, y poseer un conocimiento nítido de cuándo y cómo intervendrá el Estado en sus vidas. Esta certeza representa una necesidad de todo individuo que se rige en sus actos de conformidad con esas normas, una defensa frente a la arbitrariedad, un medio para evitar los conflictos jurídicos, así como una exigencia intrínseca del funcionamiento correcto de todo sistema. Sin embargo, no hay duda de que la certeza del Derecho ha sido y sigue siendo valorada por la seguridad de orientación que dispensa a los sujetos de Derecho a la hora de actuar, de proyectar y decidir poner en marcha un curso de acción ${ }^{14}$.

La anterior es una certeza que emana del conocimiento del contenido de las normas jurídicas que podría llamarse certeza de orientación y que debe ser distinguida de la certeza de existencia. Aspecto que depende de la conciencia de su existencia y vigencia, no de un acceso a los contenidos de la regulación jurídica ${ }^{15}$. Son, por consiguiente, dos aspectos separables, si bien la certeza de orientación no es posible sin una previa certeza de existencia de la norma, no implicando la última, necesariamente, el conocimiento del contenido. Mientras que la primera depende de las cualidades del lenguaje jurídico que hacen comprensible el significado de la precisión, claridad, publicidad, etc.; la segunda demanda la concurrencia de todos los indicios que permiten estimar que una norma posee existencia jurídica (publicación, ausencia de antinomias, jerarquía de fuentes ...).

Por otro lado, en la certeza de contenido y de existencia descansa lo que clásicamente ha sido y continúa siendo un concepto restringido de seguridad jurídica, propiamente el de la predecibilidad del Derecho. La certeza de conocimiento permite a los ciudadanos conocer, con claridad y de antemano, lo que está prohibido y permitido y, en función de ese conocimiento, organizar su conducta presente y programar expectativas para su actuación jurídica futura bajo pautas razonables de predecibilidad ${ }^{16}$. Al hacer esta aportación, el Derecho crea seguridad y confianza en la vida de cualquier organización social.

Concluyentemente, la certeza jurídica incluiría la firmeza del Derecho vigente. Además del contenido de las normas, integra la ausencia de dudas acerca de la plena vigencia de ciertas decisiones, las cuales no pueden ser muchas veces sólo expresión de la razón, sino también una decisión, en principio definitiva o con pretensión de serlo, de aspiraciones o conflictos.

13 Geiger, Theodor, Estudios preliminares de Sociología del Derecho, edic. de J.L. Monereo Pérez. Ed. Comares, Granada, 2001, p. 89.

Geiger, Estudio, cit., nota n. 13, pp. 88 y 89.

Lombardi Vallauri, Luigi, Saggio sul diritto giurisprudenziale. Ed. Giuffrè, Milán, 1975, pp. 574-577.

Pérez Luño, Antonio-Enrique, La seguridad jurídica. Ed. Tecnos, Madrid, 1994, pp. 29 y 30. 
Desde este punto de vista, Coing ${ }^{17}$ postula que la seguridad jurídica supone que los derechos, las posiciones de poder y de posesión, una vez fundadas, tienen que subsistir sin que nadie las discuta o perturbe, y que las decisiones jurídicas, una vez formuladas, deben ser mantenidas. Ello posibilita que se pueda confiar en el Derecho como una magnitud fija, sustraída a toda transformación caprichosa, en función de la que el hombre puede ordenar su vida y ponerla bajo su protección.

Pero la seguridad jurídica no reclama solamente certeza de existencia y de cognoscibilidad, sino que requiere que el Derecho tenga una eficacia regular. Aparte de hacer factible la certeza de existencia, la eficacia es en sí una reivindicación de la seguridad jurídica que, de no ser satisfecha, dejaría sin sentido a la certeza, lo cual resultaría poco satisfactorio e insuficiente si lo que el Estado establece como Derecho soliera incumplirse ${ }^{18}$. De ahí que un Derecho desobedecido no genere certidumbre de orden, ni suministre a los ciudadanos un dato desde el que poder prever la conducta de los poderes normativos ni la de los demás individuos. Una norma jurídica desatendida no crea en su ámbito de regulación seguridad del Derecho, sino del no-Derecho ${ }^{19}$.

Si la certeza normativa hace posible la predecibilidad jurídica y la certeza de la acción, la eficacia es necesaria para que haya confianza. Para Geiger ${ }^{20}$, la certeza del Ordenamiento se refiere a qué es la norma; la confianza en el ordenamiento, en cambio, hace referencia a qué fuerza tiene. La confianza de los ciudadanos en el Derecho compele a que su eficacia no quede paralizada por hechos como la ignorantia iuris, la presencia de lagunas normativas o las dudas sobre la constitucionalidad de algún precepto. O sea, la seguridad jurídica, como principio de Derecho objetivo, impone a los operadores del sistema jurídico la máxima eficacia posible de sus disposiciones ${ }^{21}$. En la medida en que las normas se convierten muchas veces en los criterios de interacción y orientación seguidos por los ciudadanos, sólo podrán seguir desempeñando dicha función social si gozan de la máxima fuerza práctica.

Por otro lado, la seguridad del Derecho exige que los poderes públicos realicen actos de producción y aplicación de las normas de una manera no arbitraria. La seguridad jurídica asevera $\mathrm{Henkel}^{22}$ - se opone a la incertidumbre, al azar, a la arbitrariedad y al desamparo frente

Coing, Helmut, Fundamentos de Filosofía del Derecho, trad. de J.M. Mauri. Ed. Ariel, Barcelona, 1976, pp. 37-39. Rodríguez Paniagua, José María, Lecciones de Derecho natural como Introducción al Derecho. Servicio de Publicaciones de la Facultad de Derecho de la Universidad Complutense de Madrid, Madrid, 1985, p. 15.

Lombardi, Saggio, cit., nota n. 15, p. 575.

Geiger, Estudios, cit., nota n. 13, pp. 89 y 90.

Como señala M. Corsale, la seguridad jurídica se considera más realizada cuanto mayor sea el grado de aplicación unívoca y de hecho de las normas (Corsale, Massimo, "Certezza del dititto e legittimazione", 1984, Sociologia del Diritto 1, p. 156; Id., Certezza del diritto e crisi di legittimità. Ed. Giuffrè, Milán, 1979, p. 38.

Henkel H., Introducción a la Filosofía del Derecho, trad. de E. Gimbernat Ordeig. Ed. Taurus, Madrid, 1968, p. 546. 
a una situación de regulación. Diferentemente, donde reina la arbitrariedad, el poder representa una fuente permanente de inseguridad, convirtiendo al ciudadano en «un súbdito incapaz de organizar su vida, pendiente siempre de escrutar el rostro de sus gobernantes para averiguar sus buenos o malos humores y poder decidir en consecuencia" ${ }^{23}$.

Según acabamos de ver, la certeza y la eficacia del Derecho se refieren a diferentes aspectos de la estructura formal, la duración y la existencia empírica de las normas; no obstante, la seguridad jurídica no descansa exclusivamente, ni siquiera ocasionalmente, en tales factores. También lo hace, quizá progresivamente, en la forma de los actos por los cuales son creadas o aplicadas esas normas. Podría admitirse que, mientras que la certeza y la eficacia son la seguridad jurídica de la norma, la ausencia de arbitrariedad es la del acto (de producción, interpretación o aplicación). La seguridad jurídica no se agota en la certeza y en la eficacia, sino que, como recalcara el Tribunal Constitucional español desde sus primeras sentencias, «es una suma de certeza y legalidad, jerarquía y publicidad normativa, irretroactividad de lo no favorable, interdicción de la arbitrariedad, [...]» $\gg^{24}$. Más aún, para Gianformaggio y Habermas ${ }^{25}$, la interdicción de la arbitrariedad no es sólo uno de los significados esenciales de la seguridad jurídica, mostrándose como la única demanda capaz de dotarla de un contenido razonablemente realizable en la actualidad.

\section{La incidencia de los precedentes en la predecibilidad de las decisiones judiciales}

La incidencia de los precedentes en la predecibilidad de las decisiones judiciales se debe ligar principalmente al principio de igualdad, habiéndose de tener en cuenta que casos iguales tengan un tratamiento similar. Su justificación por la vía de la igualdad incide en la racionalidad de la argumentación, pero el principio no significa reiterar la jurisprudencia porque no valoraríamos el contenido y seguir los precedentes no es sólo reiteración, sino apartamiento motivado. La aclaración recae en que lo esencial es el seguimiento justificado, la jurisprudencia se ha de valorar tanto para ser seguida como para separarse de ella cambiando el fundamento de su relevancia, puesto que ha pasado de pensarse como atribución de valor relevante a la

Fernández, Tomás-Ramón, De la arbitrariedad de la Administración. Ed. Civitas, Madrid, 2002, pp. 244 y 245.

24 Sentencia 27/1981, de 20 de julio, f.j. 10. En la misma línea, la Sentencia 71/1982, de 30 de noviembre, f.j. 4, dictamina que la seguridad jurídica requiere certeza en la regla de Derecho y proscribe fórmulas proclives a la arbitrariedad.

25 Gianformaggio, Letizia, "Certezza del diritto", en Studi sulla giustificazione giuridica, Ed. Giappichelli, Turín, 1986, p. 166; Habermas, Jürgen, Facticidad y validez. Sobre el Derecho y el Estado democrático en términos de teoría del discurso, trad. de M. Jiménez Redondo. Ed. Trotta, Madrid, 2008, p. 220. La negación más celebre de la seguridad jurídica se debe al realista norteamericano J. Frank. A través de una compleja interpretación psicoanalítica, este autor llegará a calificar su deseo como una manifestación de la pervivencia en el sujeto adulto del mito infantil del padre dispensador de protección y certeza absolutas (Frank, Jerome, Law and the Modern Mind. Ed. Anchor Books, Gloucester (Massachusetts), 1970). 
obligación de motivar la decisión (motivar el seguimiento y, aún más, el cambio) ${ }^{26}$. De esta manera, la explicación se desenvuelve en cuanto la actividad judicial es una actividad práctica de argumentación racional, expresiva de un compromiso entre la predecibilidad de las decisiones y la justicia vinculada a aspectos morales o práctico-generales ${ }^{27}$.

Jurídicamente, cabe asumir que un enunciado judicial general que sirve de justificación a una decisión deberá utilizarse en todas las posteriores que consistan en casos idénticos. Además, llegados a este punto, surge la duda de si podemos sostener que existan dos casos idénticos, y si, en la hipótesis negativa, podríamos concluir que los fallos de esos dos supuestos han de ser diferentes. Mas, bajo estas circunstancias, lo que se suele argüir es que, a pesar de que sólo haya relación y no plena identidad porque haya cambiado la realidad, lo normal es que esas modificaciones no se hagan relevantes a tales efectos ${ }^{28}$.

Así pues, la aplicación de los precedentes no significa seguir reglas previas. En el primer supuesto, me refiero a la forma de apreciar razones para crear reglas, de lo que se infiere que es exigible considerar una razón para otorgar una solución al caso que se presenta como similar al anterior. De gran trascendencia es aquí la analogía para dar solución a supuestos no valorados por el Ordenamiento jurídico, construyendo reglas, y para interpretar las reglas legales vigentes. Simplificadamente, la analogía sirve a estos efectos porque se funda en el desarrollo del principio cuyo contenido dicta la tesis aristotélica de que "lo igual debe ser tratado igualmente y lo desigual debe considerarse desigualmente". Sin embargo, el argumento analógico requiere de un proceso aplicativo de gran complejidad que hace que se reputen como una inferencia, o como una heurística para encontrar nuevas premisas, comprendiéndose desde la perspectiva de un procedimiento que reviste el intento de conseguir "un equilibrio reflexivo entre la regla generalizada y los juicios particulares de la analogía" 29 .

Sobre este aspecto, la solución radica en sustentar que el precedente materializa el principio de igualdad porque hace necesario que se dé un tratamiento normativo igual a los supuestos que reúnen condiciones fácticas semejantes ${ }^{30}$. La generalidad de las normas jurídicas y el

26 Moral Soriano, Leonor, El precedente judicial. Ed. Marcial Pons. Madrid, 2002, pp. 185-187; Requejo Pagés, Juan Luis, "Juridicidad, precedente y jurisprudencia", en Varios Autores, Estudios de Derecho Público en Homenaje a Ignacio de Otto, Servicio de Publicaciones de la Universidad de Oviedo, Oviedo, p. 233.

27 Moral, El precedente, cit., nota n. 26, p. 242.

28 Asís, Jueces, cit., nota n. 3, pp. 248 y 249; Gascón Abellán, Marina, 1993, "Igualdad y respeto al precedente", Derechos y Libertades 2, pp. 211-228; Vidal Marín, Tomás, 1996, "Jurisprudencia constitucional en torno al artículo 14 de la Constitución: cambio de criterio y precedente judicial”, Revista de las Cortes Generales 38, pp. 239-260.

29 Peczenik, Aleksander, Derecho y razón, trad. de E. Garzón Valdés. Ed. Fontamara, México, D.F., 2000, pp. 96 y 97.

30 Gascón Abellán, Marina, La técnica del precedente y la argumentación racional. Ed. Tecnos, Madrid, 1993, p. 59. 
mandato de aplicación uniforme van dirigidos a la realización de la seguridad y certeza jurídicas, más que a la realización del valor de la igualdad ${ }^{31}$. Para sustentar esta idea me apoyo en el rechazo continuo al precedente como enunciado judicial general. En esta dirección, no se pueden alterar sus criterios interpretativos, lo que conduciría a una petrificación de la experiencia jurídica y a cerrar toda posible evolución en la interpretación del Ordenamiento ${ }^{32}$. En resumen, nos hemos de preguntar si con el principio de igualdad en la aplicación de la ley se introduce algo parecido al autoprecedente flexible ${ }^{33}$.

Otra cuestión que creo de utilidad es que el precedente puede tener una fuerza obligatoria jurídica, con una sanción, si es que no se aplica, o de hecho, o sea, que, de no aplicarse, haya un alto grado de posibilidades de que, recurrido el caso, el tribunal al que corresponda su resolución dictamine una solución distinta ${ }^{34}$. A lo que hay que agregar que, cuando nos hallemos ante dos casos idénticos, no surge ningún problema puesto que nace la cosa juzgada, pero, si los supuestos son similares, se deben resolver de forma igual, limitándose la comparación a las diferencias en la interpretación y aplicación de las normas sin que sea extensible a la apreciación de los hechos ${ }^{35}$.

No obstante, salta la duda de qué labor desempeña la acción de los Tribunales Constitucionales. Pues bien, aun estando dentro de sus competencias el fiscalizar las resoluciones judiciales que presuntamente infringen los derechos fundamentales, percibimos que, conforme al principio de igualdad, no es posible controlar los márgenes de discrecionalidad que tienen los jueces al ejercer su función por no violar ningún derecho fundamental. Lo expresado se debe a que la exclusividad de la jurisdicción supone tener que respetar la creatividad de la igualdad en la aplicación de la ley. Limita su control en el aseguramiento de las disposiciones constitucionales y deja que sea el poder judicial el que efectúe una depuración de las opciones de creación. Por lo que, sabido que el criterio de oportunidad es constitucional, los jueces y tribunales pueden seleccionar los criterios admitidos constitucionalmente que, a su juicio, son más pertinentes y que actúan en el ámbito de la creatividad de cada una de las sentencias que $\operatorname{dictan}^{36}$.

31 Gascón, La técnica, cit., nota n. 30, p. 59.

Asís, Jueces, cit., nota n. 3, pp. 264 y 265.

Ollero Tassara, Andrés, Igualdad en la aplicación de la ley y precedente judicial. Ed. Centro de Estudios Políticos y Constitucionales, Madrid, 2005, pp. 48-52.

34 Aarnio, Aulis, Derecho, racionalidad y comunicación social. Ensayos sobre Filosofía del Derecho, trad. de P. Larrañaga. Ed. Fontamara, México, D.F., 2000, pp. 85 y 86.

35 Bilbao Ubillos, Juan María y Rey Martínez, Fernando, "El principio constitucional de igualdad en la jurisprudencia española", en Carbonell, Miguel (comp.), El principio constitucional de igualdad. Lecturas de introducción, Ed. Comisión Nacional de los Derechos Humanos, México, D.F., 2003, p. 19.

36

Requejo, "Juridicidad", cit., nota n. 26, pp. 239-243. 
Desde esta perspectiva, la cuestión se centra en que, una vez que se ha determinado la corrección constitucional del criterio seleccionado, todos los enjuiciamientos que intenten delimitar un criterio deseable de entre los que son jurídicamente posibles y estén potencialmente en la norma se han de comprender como una injerencia en el desarrollo de la función jurisdiccional. Por otro lado, en virtud del principio de la independencia judicial, se restringe el abanico de los criterios decisorios que eventualmente son vinculadores, cosa que tiene su raíz en que el juez ha de entender que los criterios concretizantes seguidos por otros órganos jurisdiccionales son directrices orientadoras a seguir, pero no vinculan. Por ende, la respuesta se encontraría en que el único modo de reducir la variedad y complejidad de los criterios decisorios es atribuir esa clase de valor a los criterios interpretativos de las normas que se ha adoptado en cada supuesto por cada órgano jurisdiccional en particular y en cuanto a las relaciones futuras que tiene, manteniéndose que el ejercicio del control ha de realizarse por la jurisdicción ordinaria por medio de los recursos. Si bien, en lo que se refiere al ámbito normativo que es de determinación jurisdiccional obligada, queda rechazado todo enjuiciamiento por tal jurisdicción, pues, en caso positivo, se produciría una violación del principio de independencia judicial. De ahí que la competencia de los Tribunales Constitucionales en la materia se explique porque se da al precedente un valor vinculador: es un parámetro que trasluce el principio de igualdad en las resoluciones judiciales ${ }^{37}$.

Matizando más, se suele postular que la relevancia constitucional del precedente descansa en ser un instrumento que sirve para apreciar la juridicidad de los pronunciamientos judiciales. Sin embargo, se muestra que este factor instrumental corresponde a la motivación de las sentencias, pues al traducirse el principio de igualdad en el requerimiento de justificar toda diferencia de trato, la verificación de su observancia en las resoluciones jurisdiccionales sólo se puede hacer si se examina esa motivación. Consecuentemente, lo elemental para corroborar que ha habido una vulneración del principio de igualdad es que la fundamentación de la sentencia sea defectuosa. Los precedentes aportan una mayor fuerza fundamentadora puesto que conllevan unos criterios de interpretación que han de estimarse por el juzgador para asegurar la reflexividad de sus nuevos criterios discrepantes. Con este enfoque, se observa que, ya que siempre se precisa que haya una fundamentación adecuada, se permite, a veces, la remisión a fundamentaciones anteriores, y que, cuando se produce un cambio de las sentencias en relación con el precedente, la demanda se circunscribe a una motivación suficientemente razonable ${ }^{38}$.

Deduciblemente, se ha de producir una fundamentación razonable y suficiente del cambio

\footnotetext{
37 Requejo, "Juridicidad”, cit., nota n. 26, pp. 244-247. Ver también López Guerra, Luis, "El Tribunal Constitucional y el principio de stare decisis", en Varios Autores, El Tribunal Constitucional, vol. II, Ed. Instituto de Estudios Fiscales, Madrid, 1981, pp. 1433 y ss.

38 Requejo, "Juridicidad", cit., nota n. 26, pp. 248-250.
} 
La predecibilidad de las decisiones judiciales

de interpretación de las normas, siendo la pregunta que procede ¿respecto de qué se ha de requerir la razonabilidad de los órganos judiciales?, y la respuesta es que la medida de su afirmación o negación descansa en qué se ha de hacer respecto de la norma aplicable al caso $^{39}$.

\section{Especial consideración del tratamiento histórico de la predecibilidad de las decisiones judiciales en el seno del realismo jurídico norteamericano}

Una vez expuestos los elementos y significados de la seguridad jurídica, creo necesario profundizar en el tratamiento histórico de la predecibilidad de las decisiones judiciales dado por el realismo jurídico norteamericano. Así pues, son reseñables las tesis, calificables de escépticas, que esgrimió Frank al propugnar que el cometido del jurista es prever el comportamiento de los jueces. Mas a Frank no le preocupaba la predicción de la interpretación de las normas, debido a que las mayores dificultades predictivas no provienen de su oscuridad, sino que provienen de la incertidumbre ante los hechos. Si los tribunales superiores se ocupan de la interpretación del Derecho, son los de primera instancia e instrucción los que fijan los hechos. Aquéllos deciden cuestiones de Derecho, éstos resuelven las cuestiones fácticas, y en esa determinación es donde se acrecientan las dificultades de predecir el comportamiento de los jueces. El litigio se decide en la fijación de los hechos, y es aquí, y no tanto o no tan sólo, en su predicción, donde la certeza y la predecibilidad es más difícil.

Todo lo que el juez o el jurado -reiteraba Frank ${ }^{40}$ - puede hacer es formarse una creencia sobre esos hechos. Esa creencia se forma después de escuchar la declaración de los testigos que han observado (o pretenden haber observado) esos acontecimientos. Los hechos, a los fines de la sentencia, no son obligatoriamente los reales, son la creencia que se forman los jueces al respecto. La verdad procesal frente a la verdad material. Y no hay seguridad alguna de que esa creencia del juez o del jurado se corresponda con la verdad de los hechos tal y como se produjeron en la realidad, puesto que el testimonio puede ser falible (los testigos no los percibieron bien, no los recuerdan con precisión, tienen dificultades para comunicarlos al tribunal o simplemente mienten) y los jueces pueden equivocarlo en la apreciación.

Por eso, Frank ${ }^{41}$ saca las siguientes deducciones del análisis de los pleitos resueltos en

Roca Trias, Encarna, 1986, "Jurisprudencia, precedentes y principio de igualdad", Revista Jurídica de Cataluña 4, pp. 841-874; Suay Rincón, José, El principio de igualdad en la justicia constitucional. Ed. Instituto de Estudios de Administración Local, Madrid, 1985, p. 188.

$40 \quad$ Frank, Jerome, Derecho e incertidumbre, trad. de C.M. Bidegain. Ed. Fontamara, México, D.F., 2001, pp. 26 y ss. Sobre el tema, ver Solar Cayón, José Ignacio, El realismo jurídico de Jerome Frank. Normas, hechos y discrecionalidad en el proceso judicial, Universidad Carlos III de Madrid-Boletín Oficial del Estado, Madrid, 2005, pp. 110 y ss.

41 Frank, Derecho, cit., nota n. 40, pp. 130 y 131. 
primera instancia: que los testigos no reaccionan uniformemente ante los acontecimientos pasados sobre los que atestiguan; que, en la mayoría de esos juicios, los testigos dan verbalmente al tribunal versiones contradictorias sobre los acontecimientos; que, a los propósitos de la sentencia, lo que llamamos hechos de un caso derivan, a lo sumo, de la creencia del juez de primera instancia o del jurado respecto de la confianza que deben merecer algunos de esos testigos y no los otros; que hay pocas uniformidades en la formación de esas creencias de jueces o jurados y ninguna regla que sirva de ayuda; que esas creencias determinan la suerte de la mayoría de los litigantes porque, en los pocos supuestos que son apelados, los tribunales superiores aceptan usualmente las de los de primera instancia. Para que las cosas sean todavía más complicadas, esas creencias suelen ser aparentes y no siempre reales. Por añadidura, las creencias, reales o aparentes, usualmente no suelen informarse; si ocurre así y la sentencia es apelada, habitualmente el tribunal superior supondrá de forma ficticia que el inferior tuvo una creencia, fundada en la selección de una parte del testimonio oral contradictorio que justifica su sentencia. Si se juntan todos estos resultados, se puede -en opinión de Frank- llegar a concluir que quienes hablan de predecir las sentencias futuras han exagerado grandemente la posibilidad de la certidumbre judicial.

En suma, la mayoría de las sentencias futuras son no pronosticables; y la impredecibilidad de la mayoría de las decisiones antes del litigio resulta de la imposibilidad de conocer por anticipado la fijación de hechos por el tribunal de primera instancia y de la incertidumbre normativa, es decir, de la vaguedad de algunos precedentes o de dudas acerca de qué precedentes aplicarán los tribunales ${ }^{42}$.

Sin embargo, también dentro del realismo jurídico norteamericano, LLewellyn cree que la predecibilidad de las decisiones judiciales es función de la regularidad del comportamiento judicial, identificándose catorce factores que la promueven, a saber ${ }^{43}$ : unos funcionarios condicionados por el Derecho; una doctrina legal; unas técnicas doctrinales conocidas; responsabilidad del personal judicial en la (realización) de la justicia; la tradición de una respuesta única para cada caso; opiniones escritas del tribunal que informan y aconsejan a los ciudadanos; a frozen record from below; asuntos limitados; procedimientos judiciales contradictorios; la práctica de decisiones colegiadas; la seguridad de la independencia judicial promovida por el ejercicio de funciones vitalicias; y a Know Bench, el estilo jurídico de la época y la conciencia del rol judicial.

De todos estos factores, los más importantes cara a la posibilidad de predicción de las

$42 \quad$ Frank, Derecho, cit., nota n. 40, pp. 136 y 137.

43 Twining, William, "The Common Law Tradition", en Karl Llewellyn and the Realist Movement, Ed. Weidenfeld and Nicolson, Londres, 1985, pp. 203-269. 
decisiones judiciales son el rol y el estilo judicial. Por lo que respecta al rol judicial ${ }^{44}$, el término que se emplea como adecuado es la imparcialidad, un término que describe una condición: no inclinarse hacia una de las partes, carecer de interés personal en el resultado. Mas cuando se emplea esta palabra la referencia es algo más, se quiere decir, como adición a lo anterior, recto. O sea, una actitud positiva y activa, el juez tiene que hacer todo lo que esté en su mano para ver el asunto con imparcialidad y con la vista puesta en las partes litigantes y en todos nosotros. Con ello se hace referencia a otra actitud, a ser abierto, a estar dispuesto a oír, a ser informado, a ser persuadido, a responder con buenas razones. El rol judicial es tan relevante porque es el mayor frente al uso de la libertad judicial. El elemento humano no queda eliminado, enmarcándose dentro de aquél, de lo que se espera que habrá un juez que cumpla con su papel.

El otro factor capital que permite o promueve la regularidad de las decisiones judiciales y, con ella, la posibilidad de predecirlas es el estilo judicial, la clase de razonamiento que se impone en cada época. No se trata, por tanto, del estilo literario, en este supuesto la referencia recae en los métodos que siguen los jueces para tomar decisiones. Dos son los posibles estilos, el formal y el gran estilo. El formal se apoya más en las normas legales que en una percepción de las demandas de la política pública («la política es para los Parlamentos; lo nuestro son las normas»). Es el que demanda una ideología ortodoxa de la que desaparece todo, salvo las normas que se aplican deductivamente al caso, mecánicamente. Por el contrario, el gran estilo deriva de la apelación del juez a la razón ${ }^{45}$.

El gran estilo minimiza la incertidumbre y reduce todo tipo de conflictos entre las demandas de la justicia y los mandatos de las autoridades. Se parte del precedente (o normas), pero el precedente no se aplica mecánicamente, se le confronta con tres variantes de razones antes de ser aceptado y aplicado: la reputación del juez que elaboró la opinión; el principio en el sentido característico del gran estilo, es decir, no sólo como principio de ordenación o de sistematización, sino como principio que da sentido; y la política, referida al examen de las consecuencias de la regla. Se trata de una «constante búsqueda de la mejor regla aplicable, que guíe el futuro, regla que tiene que construirse sobre lo mejor que nos ofrece el pasado. La búsqueda consiste en un constante re-examen y reconstrucción de una herencia que puede generar no sólo solidez, sino remedio para el presente y para el día de mañana». Los jueces que adoptan el gran estilo muestran lo que Llewellyn denomina «sentido de la situación». Examinan cada caso no como individual, sino como un caso que puede suponer dotarnos de una regla como referencia en el futuro.

44 Davies, Howard y Holdcroft, David, Jurisprudence. Texts and Commentary. Ed. Butterworths-Heinemann, Londres, 1991, p. 460.

45 Llewellyn, Karl Nickerson, The Common Law Tradition. Deciding Appeals. Ed. Little, Brown \& Co, BostonToronto, 1960, pp. 203 y ss. 


\section{Algunas conclusiones}

Después de lo visto, es claro que los parámetros que dirigen la predecibilidad del Derecho son sumamente variables y se condicionan por la amplitud que se dé a la discreción judicial. Esa discreción es posible unirla a ciertas cualidades personales de los jueces cuando desempeñan su función, al ser la aplicación del Derecho una actividad que requiere las cualidades de la sensatez y la prudencia. Otra designación es la que da cuenta de las situaciones a las que el Derecho no otorga una solución clara, precisándose un conocimiento del lenguaje normativo para llegar a identificar la respuesta jurídica correcta.

También se entiende por discreción judicial el margen de libertad que posee el órgano de adjudicación en la determinación de los hechos. Esta noción se une a los problemas de naturaleza epistémica porque hay una falta de información para determinar la versión que más se acerca a la realidad. Además, hablamos de discreción judicial como definitividad cuando nos referimos al carácter de algunas decisiones judiciales, caso de las que no están sometidas a revisión y hacen referencia a atribuciones de competencias relativas a la instancia a la que corresponde declarar en último grado, la cual es concretada por el Derecho. Finalmente, existe una discreción fuerte, según la terminología de Dworkin, que remite a la elección entre variados cursos de acción que tienen igual nivel de validez y admisibilidad, y que debe distinguirse de la que es extensible a los ámbitos en los que la autoridad competente deja explícitamente la determinación del resultado de su decisión al arbitrio de los jueces ${ }^{46}$.

Asimismo se concluye que la problemática abordada en la presente investigación reside, en gran parte, en la interpretación como una de las principales actividades que tiene que practicar el juez. Estrictamente, supone atribuir un significado a una formulación normativa que ofrece dudas; y, ampliamente, se llama interpretación a cualquier operación por la que se atribuye significado a una formulación normativa con independencia de que existan o no dudas ${ }^{47}$. Como esgrime Guastini ${ }^{48}$ y según se desprende de este trabajo, quien adopta una concepción restrictiva tiende a ocultar el componente volitivo de la actividad interpretativa, partiendo de la premisa de que los términos tienen normalmente una significación clara que debe descubrirse y reconocerse. Por el contrario, quien adopta una concepción amplia, parte de que el significado de las palabras viene atribuido por quienes ordinariamente usan tales expresiones. Su significación es mudable y toda decisión interpretativa tiene algo de discrecional.

De este modo, apreciamos que la justificación que deben realizar los jueces reside en que

\footnotetext{
46 Iglesias Vila, Marisa, El problema de la discreción judicial. Una aproximación al conocimiento jurídico. Ed. Centro de Estudios Políticos Constitucionales, Madrid, 1999, pp. 25 y ss.

47 Troper, Michel, La Filosofía del Derecho, trad. de T. García-Berrio. Ed. Tecnos, Madrid, 2004, pp. 103 y ss.

48 Guastini, Riccardo, Le fonti del diritto e l'interpretazione. Ed. Giuffrè, Milán, 1983, pp. 335 y ss.
} 
la estructura de lo jurídico se presenta como lógicamente analizable. En apoyo a la tesis de Bobbio $^{49}$, uno de los motivos que insistentemente ha aproximado la lógica y el Derecho ha sido la convicción de que el Ordenamiento jurídico nutre, con preferencia, de juicios analíticos a juicios de hecho y de valor. Aquí no hay que olvidar que, a la par que la lógica clásica se estatuye en Ciencia de las leyes del pensamiento y en estudio de naturaleza filosófica, encaminado a mostrar las condiciones de validez de la actividad racional y de los productos objetivados de la misma, del conocimiento científico-filosófico y de su verdad ontológica; se abre camino el apego por las leyes y condiciones que garantizan el enlace sistemático de sus resultados. En ese escenario hay que insistir en que la lógica sirve para indicar el conjunto de las reglas del pensamiento y de su forma de $\operatorname{actuar}^{50}$. Consiguientemente, la pregunta previa para analizar la predecibilidad de las decisiones judiciales es qué función desempeñan los jueces en la sociedad y si hay algo en común entre los sistemas jurídicos que corresponden a formaciones histórico-sociales distintas. Para contestar, es necesario reflexionar sobre si la inteligibilidad de un sistema se une al descubrimiento de su racionalidad y sobre si las razones jurídicas de las que se asiste son capaces de coexistir, confluyendo ambas contestaciones en la dinámica de la producción normativa.

Ahora bien, se evidencia que la ausencia de delimitación completa de la extensión de un concepto y la indeterminación semántica parecen irreductibles, vislumbrándose que la claridad u oscuridad de un texto es relativa a su contexto de enunciación y al contexto de aplicación. Materialmente, nos movemos en el debate entre las tesis imperativistas, que contemplan al Derecho desde el ángulo del poder, y las anti-imperativistas, que lo contemplan desde la libertad $^{51}$.

Con estas coordenadas, en los Estados de Derecho la legislación es la instancia jurídica que se encarga de introducir cambios, reflejando o guiando el cambio social; mientras que, en el campo judicial, la interpretación permite un margen para introducir ciertos cambios, dentro de lo que permita el sistema ${ }^{52}$. Los cambios que sufre el modelo aplicativo del Derecho rompen con la concepción del estricto formalismo, creándose espacios de no-Derecho relacionados con fines y estrategias de naturaleza ajena a la jurídica, tales como sociales, económicas, políticas, etc., que, a su vez, tienen un gran peso en la realización de los principios que regulan el nuevo Derecho ${ }^{53}$.

49 Bobbio, Norberto, 1962, "Diritto e logica", Rivista Internazionale di Filosofia del Diritto XXXIX/I, pp. 9 y ss.

50 Ver Bochenski, Joseph M., Historia de la lógica formal, trad. de M. Bravo Lozano. Ed. Gredos, Madrid, 1985.

$51 \quad$ Reale, Miguel, Introducción al Derecho, trad. de J. Brufau Prats. Ed. Pirámide, Madrid, 1989, pp. 249 y ss.;

Soriano Díaz, Ramón, Compendio de Teoría general del Derecho. Ed. Ariel, Barcelona, 1993, pp. 71 y ss.

52 Atienza, Manuel, El sentido del Derecho. Ed. Ariel, Barcelona, 2003, pp. 169 y ss.

53 Picontó Novales, Teresa, En las fronteras del Derecho. Estudio de casos y reflexiones generales. Ed. Dykinson, Madrid, 2000, p. 162. 
Con respecto al sustrato sociológico de un sistema jurídico, hay que tener en cuenta que se abordan las fuerzas reales y los factores infra y supraestructurales del nacimiento, conservación, transformación, destrucción y aniquilación del Derecho, apareciendo los problemas de su génesis sociológica y de las corrientes determinantes, al igual que ocurre con las relaciones que están presentes en los cambios sociales y jurídicos. Desde esta comprensión, las preguntas que surgen al término de nuestro estudio son: ¿qué clase y grado de sincronización hay?, ¿cuándo va el Derecho por detrás o por delante de los intereses, valores o aspiraciones de una sociedad?, o ¿cuáles son los factores reales del retraso del Derecho en ciertas circunstancias? En consecuencia, la influencia sobre la realidad social arranca de que desde la legalidad es posible producir e impedir, o por lo menos frenar, alteraciones, al hilo de lo que se desprende la relevancia del control ejercido por las normas positivas y la función de los jueces ${ }^{54}$.

Mas estaba en lo cierto el realismo jurídico norteamericano al conceptuar el Derecho como realidad que sufre un cambio incesante, apoyada en la actividad judicial creativa. Que se orienta a cumplir fines sociales, no mezclando temporalmente el ser con el deber ser, y conviniendo la separación de las reglas atinentes a la conducta (rules for doing) o preceptos (precepts), de las reglas de procedimiento (rules of doing) o práctica judicial (practices). Así, las formulaciones prescriptivas no serían el factor determinante de las decisiones de los tribunales, habiéndose de superar la convicción de que merece la pena agrupar casos y situaciones legales en categorías fijas practicadas en el pasado. Semejantemente, hay que subrayar que toda la evaluación de una parte o sector del Derecho se debe hacer en función de sus efectos ${ }^{55} 56$. Interesa el funcionamiento real de los tribunales, los aspectos que inciden en sus decisiones y el peso que tienen los factores extrajurídicos. En este orden de ideas, las normas son un factor relevante, pero, desde luego, no el exclusivo ni tampoco el decisivo, dado que el Derecho goza de un alto grado de incertidumbre en virtud de la ambigüedad normativa, de la dificultad verificadora de los hechos alegados en el proceso y de que, casi siempre, se pueden aplicar distintas regulaciones sin que el Derecho diga cuál ha de ser la elegida $^{57}$

Díaz García, Elías, Sociología y Filosofía del Derecho. Ed. Taurus, Madrid, 1993, pp. 201 y ss.

Sobre le tema, ver Garrido Gómez, M. Isabel, Criterios para la solución de conflictos de intereses en el Derecho privado. Ed. Dykinson, Madrid, 2002, p. 102; Zapatero, Virgilio y Garrido Gómez, M. Isabel, El Derecho como proceso normativo. Lecciones de Teoría del Derecho. Servicio de Publicaciones de la Universidad de Alcalá, Alcalá de Henares (Madrid), 2007, pp. 63 y ss. 
La predecibilidad de las decisiones judiciales

Revista IUS Et PRAXIS - AÑo 15 - № 173 